\title{
Parathyroid Hormone Response in Newborn Infants during Exchange Transfusion with Blood supplemented with Citrate and Phosphate: Effect of iv Calcium ${ }^{(37)}$
}

\author{
PETER WIELAND, GABRIEL DUC, ULRICH BINSWANGER AND JAN A. FISCHER (40) \\ Neonatal Unit, Departments of Obstetrics and Pediatrics, University, Zurich, Switzerland, Research Laboratory for \\ Calcium Metabolism, Departments of Orthopedic Surgery and Medicine, University, Zurich, Switzerland, and \\ Nephrology Unit, Department of Medicine, University, Zurich, Switzerland
}

\begin{abstract}
Summary
We studied secretory parathyroid function in 16 newborn infants, aged 34-137 hr, before, during, and after exchange transfusion with a radioimmunoassay recognizing mainly intact human parathyroid hormone-(1-84) (hPTH-(1-84)). Before the exchange transfusion, serum calcium was normal or decreased, whereas parathyroid hormone (PTH) was within or above the range of normal adults. Serum PTH approached a maximum at decreased serum ionized and total calcium levels which were close to the normal range. During the early period of the exchange transfusion, serum ionized calcium was decreased as a result of the administration of considerable amounts of phosphate and citrate in the donor-blood and PTH was raised to levels seen in hypocalcemic infants before the exchange transfusion. Thereafter, serum ionized calcium remained low, whereas mean PTH concentrations were below basal levels. These inappropriately low PTH levels in relation to lowered serum-ionized calcium concentrations are probably the result of inadequate PTH secretion, which is enhanced by withdrawal of large amounts of presumably biologically active PTH-(1-84) during the exchange transfusion. Serum total calcium, on the other hand, was raised during the exchange transfusion probably as a result of calcium mobilization, and the net calcium balance expressed as the difference of calcium administered and in the withdrawn blood was negative. Even though serum ionized calcium decreased to levels below $2.5 \mathrm{mg} / \mathrm{dl}$ during the exchange transfusion, tetany was never observed, iv injections of calcium during the exchange transfusion caused temporary increases in total, but not in ionized calcium levels and shortening of Q-oTc intervals lasting for less than $1 \mathrm{~min}$. We, therefore, advocate that iv calcium injections at regular time intervals during the exchange transfusion with donor blood preserved in citrate and phosphate should no longer be recommended as a prophylactic measure for preventing the decrease in serum-ionized calcium.
\end{abstract}

\section{Speculation}

Parathyroid secretory function is inversely related to serum calcium concentrations in newborn infants. Serum PTH secretion is maximal at serum-ionized and total calcium concentrations close to the normal range despite further reduction to more markedly hypocalcemic levels. Transitory hypoparathyroidism occurs during exchange transfusion as a result of the removal of considerable amounts of biologically active PTH-(1-84).

Evidence obtained by David and Anast (10) indicates that serum PTH is low or undetectable during the first $48 \mathrm{hr}$ of life, whereas after $48 \mathrm{hr}$, there are parallel increases in PTH as well as in total and ionized calcium levels. Tsang et al. (34) and Hillman et al. (19) reported a significant negative correlation between cord serum calcium and PTH levels after $24-48 \mathrm{hr}$ of age.

In newborn infants, exchange transfusion with donor blood preserved in citrate, or citrate and phosphate are used to relieve hyperbilirubinemia $(12,21,35,36)$. This results in a decrease in ionized $(11,27,33)$ and in a slight increase in total calcium concentrations $(11,27)$. The available evidence indicates that a fall in ionized rather than in total calcium is responsible for a stimulation of PTH secretion induced by the administration of phosphate or of blood preserved in citrate during exchange transfusion $(11,14,25,29,33)$.

The purpose of the present study was twofold: 1) to investigate parathyroid secretory function in newborn infants before, during, and after exchange transfusion; and 2) to assess, whether iv calcium supplementation can prevent the decrease in serum ionized calcium as well as the prolongation of Q-oTc intervals $(4,9)$ during exchange transfusion with donor blood preserved in citrate and phosphate. To this end, we studied basal PTH levels and PTH responses to falls in serum-ionized calcium. Finally, we calculated the net balance of calcium, magnesium, and PTH during the exchange transfusions as the difference of iv injected calcium and the amounts in the donor, and the withdrawn blood.

\section{INFANTS AND METHODS}

\section{INFANTS AND PROCEDURES}

Sixteen 34- to 137-hr-old infants with hyperbilirubinemia requiring exchange transfusion, but without history of intrauterine or neonatal asphyxia or signs of respiratory distress syndrome and septicemia, were studied before, during, and after exchange transfusions (Table 1). The hyperbilirubinemia was caused by incompatibilities of $\mathrm{ABO}$ blood groups in eight and rhesus in one infant, in one infant by glucose-6-phosphate dehydrogenase deficiency and was of unknown origin in another six infants. The exchange transfusions were performed via umbilical vein catheter with blood $(200 \mathrm{ml} / \mathrm{kg})$ at a rate of $2-3 \mathrm{ml} / \mathrm{kg} / \mathrm{min}$. Donor blood, $380-420$ $\mathrm{ml}$, was preserved in $56 \mathrm{ml}$ of a solution containing $183 \mathrm{mg}$ citric acid monohydrate, $1472 \mathrm{mg}$ sodium citrate dihydrate, $124 \mathrm{mg}$ dihydrogen phosphate monohydrate, and $1300 \mathrm{mg}$ dextrose (CPD blood) (16) (Swiss Red Cross, Berne, Switzerland). In nine infants, $4.5 \mathrm{mg}$ calcium as calcium gluconolactobionate $(0.5 \mathrm{ml}$ of a $10 \%$ solution) (Sandoz, Basle, Switzerland) was administered iv within $1 \mathrm{~min}$ after every $160 \mathrm{ml}$ of exchanged blood (Fig. 1), whereas the remaining seven infants did not receive calcium supplementation. The infants of these two groups were selected alternately, and they were not statistically different for their hyperbilirubinemia (not shown), gestational and postnatal age, and birth weight. Blood samples were withdrawn via umbilical vein catheter before, during, 
WIELAND $E T A L$.

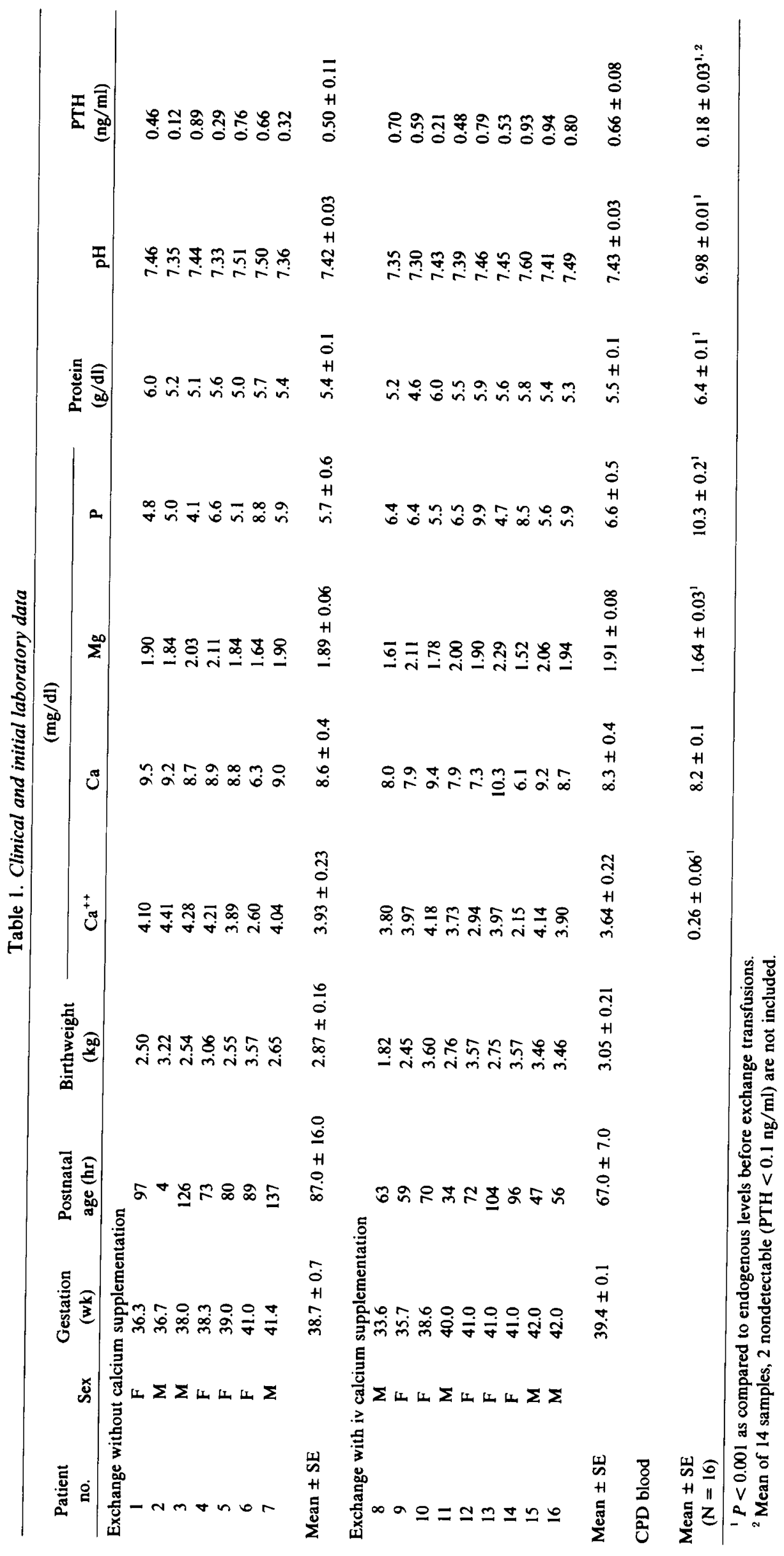




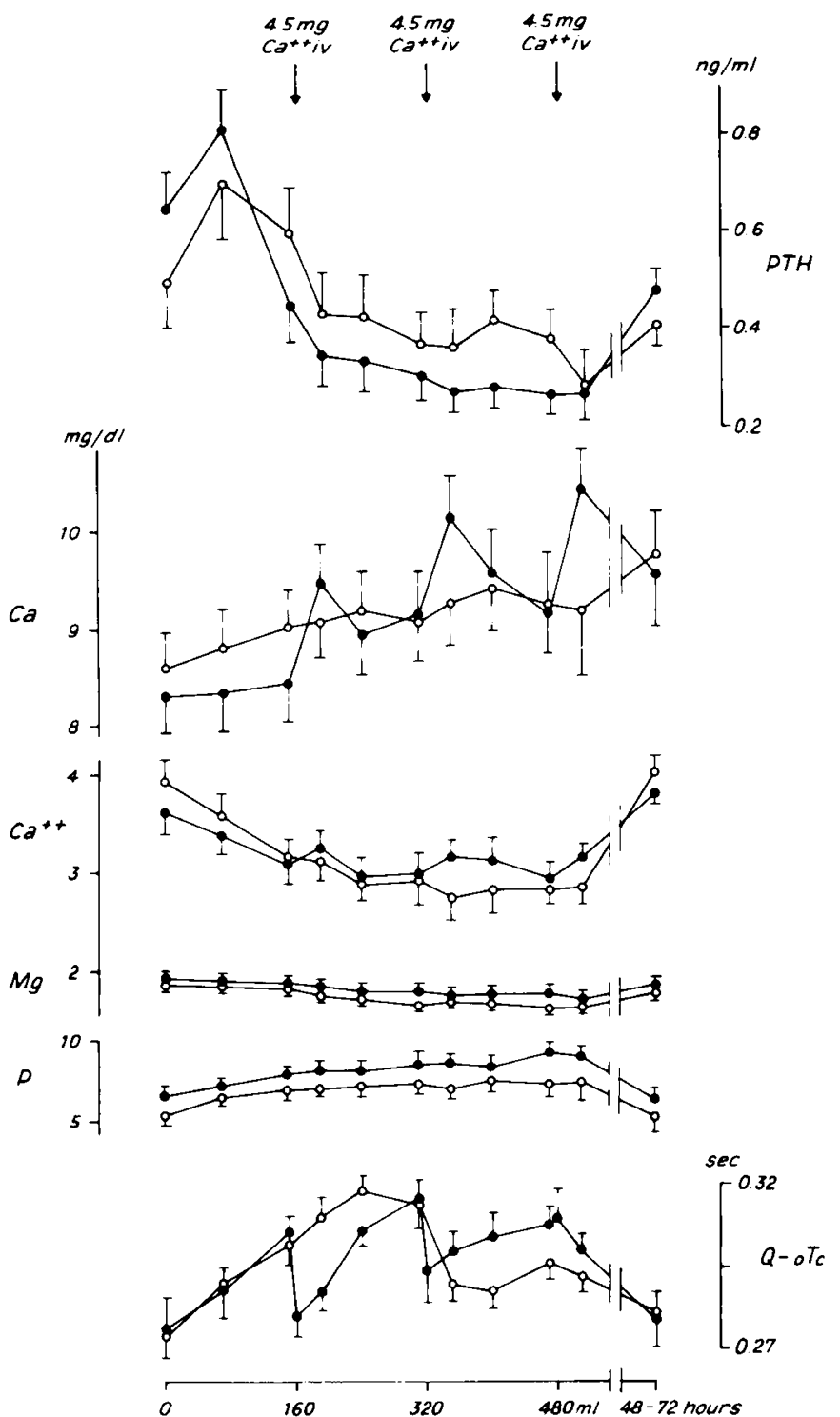

Fig. 1. Serum PTH, total $(\mathrm{Ca})$, and ionized $\left(\mathrm{Ca}^{++}\right)$calcium, magnesium $(\mathrm{Mg})$, inorganic phosphorus $(\mathrm{P})$, and Q-oTc intervals (mean $\pm \mathrm{SE}$ ) before, during, and after exchange transfusion with CPD blood without $(O)$ and with (O) iv calcium supplementation in 16 newborn infants. Abscissa: $\mathbf{m l}$ of exchanged blood (the exchange lasted from 1-1.5 hr), a final sample was taken between 48 and $72 \mathrm{hr}$ after the exchange transfusions.

and 48-72 $\mathrm{hr}$ after the end of the exchange transfusion as shown in Figure 1. Sampling intervals were defined by the volume of exchanged blood; the exchange lasted from 1.0-1.5 hr. In order to remove any traces of donor blood and of injected calcium, the initial $10 \mathrm{ml}$ of blood had to be discarded (not shown). The samples were put immediately under oil without anticoagulant and centrifuged at $4^{\circ} \mathrm{C}$. The serum was separated and kept at $-20^{\circ} \mathrm{C}$ until analyzed.

The net balances of calcium, magnesium, and PTH during the exchange transfusion were calculated as the difference between iv injected calcium and the amounts in the donor blood, and the amounts withdrawn. The infants were fasted during the exchange transfusions and urinary and fecal excretions were neglected. The data are charted according to Reifenstein et al. (28) and related to kg body weight (Fig. 2).

\section{GEL FILTRATION OF PARATHYROID HORMONE OR SERA}

Columns of Bio-Gel P-150 (100-200 mesh) (Bio-Rad Laboratories, Richmond, CA), $1.6 \times 100 \mathrm{~cm}$ were used for gel filtration of a $1 \%$ pure ureatrichloroacetic acid extract (hPTH-(TCA)) of human parathyroid tumors previously described (15), as well as of serum samples. The columns were equilibrated with eluant consisting of $0.2 \mathrm{M}$ ammonium acetate $(\mathrm{pH} \mathrm{4.7)}$ and human serum albumin (Swiss Red Cross, Berne, Switzerland) $(2.5 \mathrm{mg} / \mathrm{ml})$ at $4^{\circ} \mathrm{C}$. The void volume was determined with Blue Dextran (Pharmacia, Uppsala, Sweden), and the salt volume with $\mathrm{Na}\left[{ }^{125} \mathrm{I}\right]$. Gel filtration was accomplished with 5-ml samples to which radioiodinated bovine PTH-(1-84) (bPTH-(1-84)), bPTH-(1-34), human calcitonin-(1-32), and $\mathrm{Na}\left[{ }^{125} \mathrm{I}\right]$ were added (flow rates $5 \mathrm{ml} / \mathrm{hr}, 2$ $3 \mathrm{ml}$ fractions). Radioactivity was determined in an automatic $\gamma$ well spectrometer (Nuclear-Chicago Corp., Des Plaines, IL). The amount of each labeled marker was kept low enough not to interfere with radioimmunologic determinations.

\section{ANALYTICAL METHODS}

PTH in column effluent fractions and in serum was determined radioimmunologically with $\left[{ }^{131} \mathrm{I}\right] \mathrm{bPTH}-(1-84)$ as the ligand and a $10 \%$ pure extract of human parathyroid tumors as standard (hPTH-(1-84)G-100) $(3,15)$. Antibodies were obtained in a goat on day 848 (goat 16 , day 848 ), which was immunized with seven injections of hPTH-(TCA) totalling $24 \mathrm{mg}$ (or $0.24 \mathrm{mg}$ immunoreactive $\mathrm{PTH})$, followed by two injections of $0.01 \mathrm{mg}$ bPTH-( $1-$ $84)$; the same bPTH-(1-84) was used as the ligand. Inhibition curves of hPTH-(1-84)G-100 and of the synthetic hPTH-(1-34) $(2,32)$ peptides with structures derived by Brewer $e t$ al. $(7)$ and by Niall et al. (26) were parallel between 90 and 40\% "trace" suggesting that the antibodies recognized the $\mathrm{NH}_{2}$-terminal region of the hPTH-(1-84) molecule (Fig. 3). The volume of the individual blood samples was insufficient for gel filtration analysis of PTH. We have, therefore, retained and pooled constant fractions of 5 $\mathrm{ml}$ serum from all the samples of removed blood during the exchange transfusion. On gel filtration analysis of PTH in this pool of removed blood, a peak coeliciting with intact hPTH-(184) and late eluting fragments were mainly recognizable (Fig. 4). The 7'000 mol wt COOH-terminal fragment described in the literature $(15,17,30,31)$ as an important circulating form was hardly visualized, unless the shoulder trailing from the intact PTH peak represented part of it. In this instance, the CPD donor blood had undetectable PTH. A comparable pattern was observed in the pool of removed blood obtained from all the other neonates and in four samples of unused CPD blood. Unfortunately, we did not retain sufficient amounts of the transfused CPD blood for gel filtration analysis. It appears, therefore, that the antibodies used in the present report for the analysis of serum PTH mainly recognized the intact hPTH-(1-84) molecule. Serum levels of PTH were also measured in peripheral serum of 30 adult control subjects. They showed no history of bone or kidney disease and

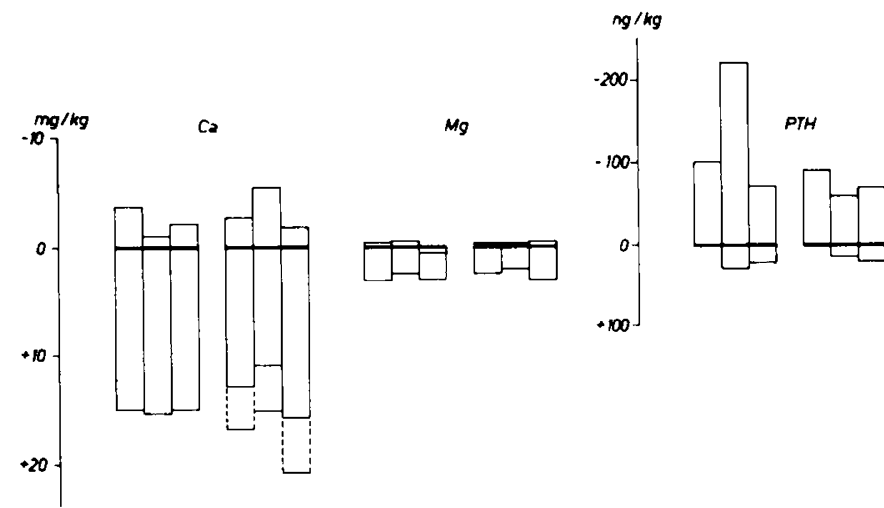

Fig. 2. Balance of total calcium, magnesium, and PTH infused and removed per $\mathrm{kg}$ body weight in six newborn infants during exchange transfusions without and with iv calcium supplementation. The amounts administered (as measured in CPD donor blood) are shown below the zero line and the amounts withdrawn as the whole columns. Iv calcium supplementation is represented with dashed lines. 


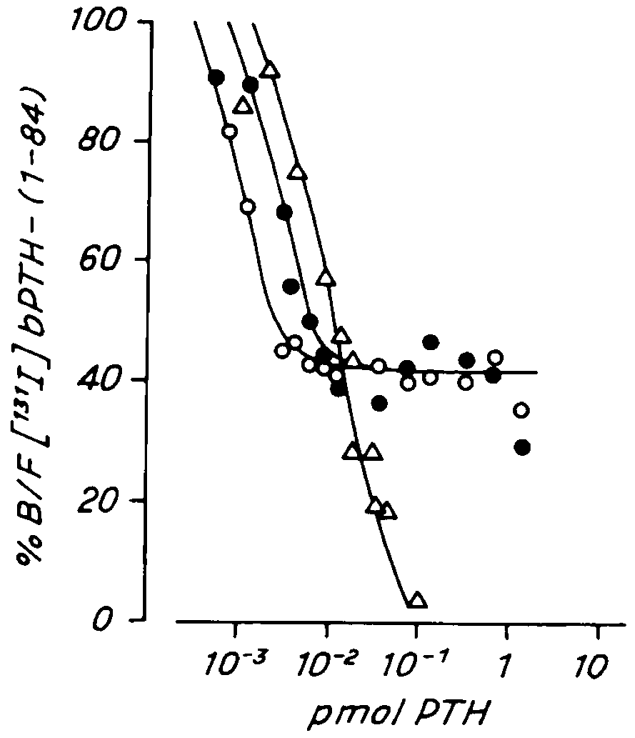

Fig. 3. Qualitative properties of antibodies to extracted human and bovine PTH. Inhibition of the specific binding of $\left[{ }^{131} \mathrm{I}\right] \mathrm{bPTH}-(1-84)$ to anti-hPTH-(TCA) and bPTH-( $(1-84)$ obtained from goat 16 , day 848 and diluted 1:75'000. Ordinate: percent initial B/F (ratio of antibody bound and free $\left[{ }^{131} \mathrm{I}\right]$ bPTH-(1-84) without inhibitor added). Inhibitors: hPTH(1-34) (26) (O), hPTH-(1-34) (2) (O), and hPTH-(1-84) G-100 ( $\triangle$ ).

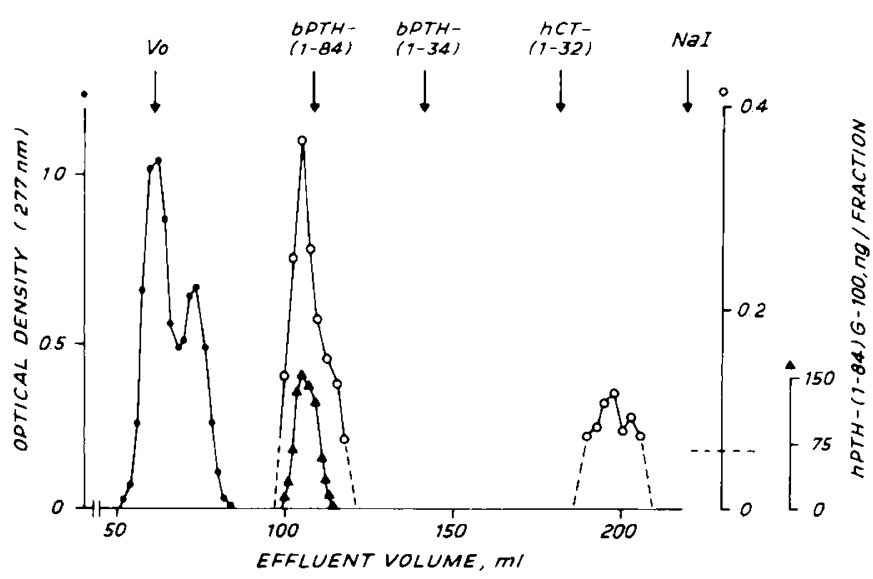

Fig. 4. Characterization of hPTH-(TCA) and of PTH in the pool of removed blood (see Methods) from a newborn infant during exchange transfusion by chromatography on Bio-Gel P-150. In this instance, the CPD donor blood had undetectable PTH. [ $\left.{ }^{131} I\right]$ bPTH-(1-84), -(1-34), and $\left[{ }^{131} \mathrm{I}\right]$ human calcitonin-(1-32) $(\mathrm{hCT})$, and $\mathrm{Na}\left[{ }^{125} \mathrm{I}\right]$ were added to $5 \mathrm{ml}$ samples of hPTH-(TCA) or serum. $1.6 \times 100 \mathrm{~cm}$ column, $0.2 \mathrm{M}$ ammonium acetate, $\mathrm{pH} 4.7$, and human serum albumin $2.5 \mathrm{mg} / \mathrm{ml}$ as eluant, 5 $\mathrm{ml} / \mathrm{hr}$ flow rate, $2-3 \mathrm{ml}$ fractions. Optical density readings of $2 \mathrm{ml}$ effluent fractions diluted 1:100 (.). hPTH-(TCA) $(\Delta)$ and serum PTH $(O)$ were analyzed with the system characterized in Figure 3. The stippled line indicates the sensitivity limits of the radioimmunoassay.

they had normal serum concentrations of ionized and total calcium (Fig. 5), as well as magnesium, inorganic phosphorus, alkaline phosphatase, creatinine, and PTH as estimated with anti-hPTH(TCA) specific for the COOH-terminal part of hPTH-(1-84) (15 and unpublished results). The coefficient of variation of a measurement within the same assay was up to $12 \%$ and between assays up to $14 \%$.

Serum ionized calcium was determined with a flow through electrode system (Orion Research Inc., Cambridge, MA, Model 99-20; coefficient of variation $1.2 \%$ ), total calcium and magnesium by atomic absorption flame spectrometry (Perkin-Elmer Corp., Norwalk, CN, Model 305; coefficients of variation 0.8 and $1.3 \%$, respectively), inorganic phosphorus photometrically with malach- ite green as indicator (20) (Hoffmann-La Roche, Basle, Switzerland; coefficient of variation $2.6 \%$ ), protein with a refractometer (AO-Instrument Company, Buffalo, NY; coefficient of variation $1.1 \%$ ) and $\mathrm{pH}$ with an Orion Model $801 \mathrm{pH}$ meter (coefficient of variation $1.0 \%$ ).

Before and after the exchange, as well as during blood sampling, ECG's were obtained for monitoring heart rates and measurement of Q-oT intervals. They were corrected for heart rate according to Bazett's formula (4) $\left(Q-o T c=Q-o T / \sqrt{R-R^{\prime}}\right)$. A statistically significant negative correlation between serum ionized calcium concentration and Q-oTc intervals $(n=43, r=0.49, \mathrm{P}<0.001)$ suggests that meaningful results were obtained with the calcium specific electrode.

Statistical evaluation among groups was performed with the paired- $t$ test and between groups with the Student's $t$ test, as well as with correlation analysis and calculation of the coefficient of variation (13).

\section{RESULTS}

Laboratory data obtained before the exchange transfusion are summarized on Table 1 . Serum ionized and total calcium were normal or decreased, whereas PTH levels were within or above the range of normal adults. A negative relationship between serum ionized and total calcium, and PTH concentration was observed with PTH levels approaching maximal concentrations, when the serum calcium was only slightly decreased (Fig. 5). Mean basal serum ionized and total calcium, magnesium, phosphorus, proteins and $\mathrm{pH}$, and PTH levels were not significantly different in the two groups of infants studied with and without iv calcium supplementation during the exchange transfusions $(P>0.1)$.

In CPD blood, the mean serum ionized calcium concentration was $0.26 \pm 0.06 \mathrm{mg} / \mathrm{dl}$ as compared to endogenous levels of 3.77 $\pm 0.16 \mathrm{mg} / \mathrm{dl}$ before the exchange transfusion, whereas total calcium concentrations were not significantly different from endogenous pretransfusion levels (Table 1). Serum magnesium and $\mathrm{pH}$ were lower and inorganic phosphorus and proteins higher in the donor than in the neonatal blood. The high concentration of inorganic phosphorus was caused by the addition of phosphate to the CPD donor blood. PTH was undetectable in two samples of CPD blood and ranged from $0.09-0.38 \mathrm{ng} / \mathrm{ml}$ in 14 samples as compared to endogenous levels of $0.12-0.94 \mathrm{ng} / \mathrm{ml}$ before exchange transfusion.

During the entire exchange transfusion, serum ionized calcium levels were reversibly decreased $(P<0.01$ to $<0.001)$ and the $Q-$ oTc intervals prolonged as compared to before and after the exchange transfusion $(P<0.01$ to $<0.001)$ (Fig. 1). The serum total calcium, on the other hand, was significantly increased $(P$ $<0.05$ to $<0.001$ ), but only after $170 \mathrm{ml}$ exchanged blood. Serum inorganic phosphorus levels were reversibly increased $(P<0.01$ to $<0.001$ ) due to the administration of phosphate to the donor

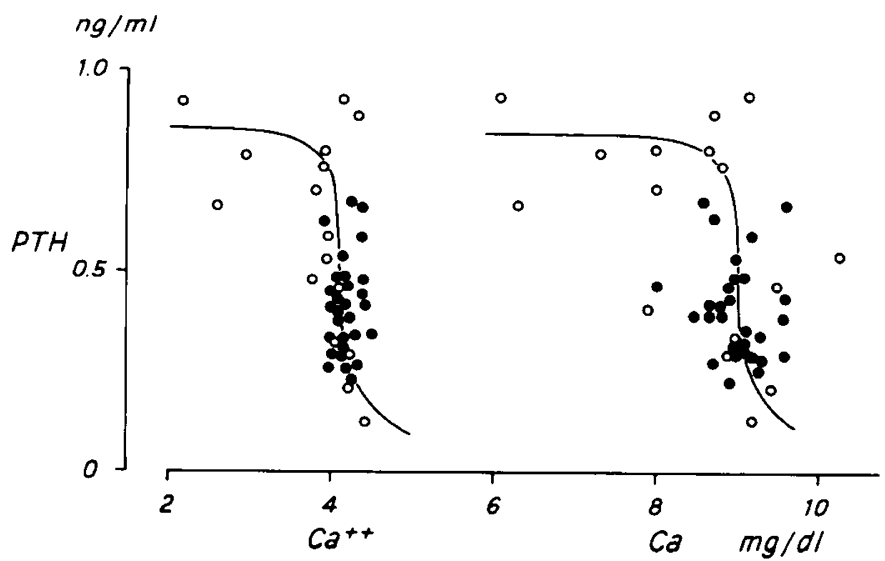

Fig. 5. Relationship between concentrations of serum-ionized $\left(\mathrm{Ca}^{++}\right)$, and total $(\mathrm{Ca})$ calcium, and PTH in newborn infants $(\mathrm{O})$ before exchange transfusion, and in adult control subjects (๑). 
blood. Furthermore, there were small and reversible falls of serum magnesium levels beginning after $190 \mathrm{ml}$ of exchanged blood $(P$ $<0.05$ to $<0.001$ ). Serum proteins and $\mathrm{pH}$ remained unchanged (not shown).

As a result of the fall in serum ionized calcium concentrations, PTH increased significantly after the first $70 \mathrm{ml}$ of exchanged blood $(P<0.005)$. PTH responses were unrelated to the gestational age (34-42 wk) of the infants (not shown). At this time, PTH levels were inversely related to the serum ionized calcium concentrations. PTH levels were maximal already at slightly decreased serum ionized calcium concentrations and the relationship between serum ionized calcium and PTH was similar to that before the exchange transfusions. Thereafter, serum ionized calcium remained low, whereas mean PTH levels were somewhat lower than before the exchange transfusions, but the difference was not statistically significant $(P>0.05)$.

The iv administration of calcium gluconate caused significant, but transitory increases of the total calcium levels $(P<0.01$ to $<$ 0.001 ), whereas the serum ionized calcium responses were much smaller $(P>0.05)$. After the first and the second injection of calcium, Q-oTc prolongations were reversibly shortened, but not normalized $(P<0.05$ to $<0.01)$, after the third injection Q-oTc intervals remained unchanged. Magnesium, phosphate, and PTH levels remained unchanged after the calcium injections. There were no significant differences between mean values of all the parameters studied in the groups of infants treated with and without iv calcium supplementation.

As shown in Figure 2, the balance of calcium was negative in six of the infants examined: the babies lost $10-20 \mathrm{mg}$ calcium per exchange, regardless of whether calcium was administered iv or not. The balance of magnesium was in equilibrium, whereas considerable amounts of PTH were lost during the exchange transfusion. The immunoreactive PTH administered in the donor blood and the PTH in the pool of withdrawn blood (see Methods) was largely intact hPTH-(1-84) (Fig. 4).

\section{DISCUSSION}

Serum PTH was measured with a recently developed radioimmunoassay system including antibodies raised to an extract of human parathyroid tumors which primarily recognized presumably biologically active intact hPTH-(1-84). Our results confirm previous investigations, that both in premature and in term infants between 34 and $137 \mathrm{hr}$ of postnatal age, serum ionized and total calcium concentrations are normal or decreased, and PTH within or above the range of normal adults $(10,11,19,34)$. Serum PTH approached a miximum in our study at decreased serum ionized and total calcium concentrations close to the normal range. A similar relationship between serum calcium and PTH levels has been previously observed in cows and rats $(5,6,8,24)$. A weak, but significant negative correlation between cord ionized and total calcium, and PTH serum concentrations has been reported in infants between 24 and $48 \mathrm{hr}$ of age $(19,34)$.

Furthermore, we studied acute PTH responses to falls in serum ionized calcium levels during exchange transfusions. As a result of the administration of blood containing considerable amounts of phosphate and citrate as complexing anions, serum-ionized calcium was significantly lowered and PTH increased during the early period of the exchange transfusion. Other causes of the decrease in serum-ionized calcium such as changes in serum proteins and $\mathrm{pH}$ were ruled out. Previous investigators have noted raised PTH levels during and after exchange transfusion $(11,33)$. The low, but constant values of ionized calcium during the second half of the exchange transfusion, despite additional dilution with CPD donor blood containing minimal amounts of ionized calcium, suggest that ionized calcium was mobilized through catabolism of citrate and possibly under the influence of PTH. Falling levels of PTH during the exchange transfusions were probably caused by the withdrawal of large amounts of PTH as compared to a small quantity of PTH administered in the donor blood (25). In our hands, a large proportion of the PTH withdrawn represents intact hPTH-(1-84). The fall of plasma PTH may also be caused by an inadequate secretory response of the parathyroid glands caused by falls of the serum levels of ionized magnesium (1). The stability constants between citrate and phosphate, and calcium and magnesium are similar (23), suggesting that not only the levels of ionized calcium, but also of magnesium may have decreased.

Iv injections of calcium administered at regular time intervals during the exchange transfusions were ineffective in preventing the fall in ionized calcium although a transient increase was occasionally noted shortly after the injections. The progressive decrease in ionized calcium was associated with a prolongation of Q-oTc intervals, indicating a measurable effect of the procedure on cellular excitability, whereas the heart rate remained stable. The shortening of Q-oTc intervals appears to be of little clinical benefit, inasmuch as it lasts less than $1 \mathrm{~min}$. The question as to whether higher doses of calcium would be effective in preventing a decrease in ionized calcium cannot be answered by the present study. Iv injections of more than 10 times higher amounts of calcium during exchange transfusions with CPD donor blood caused an increase in total calcium of up to $15.5 \mathrm{mg} / \mathrm{dl}(21)$. In view of the high serum phosphate concentration precipitation of calcium salts in soft tissues appears possible (18). The practice of injecting calcium during exchange transfusions remains routine in many neonatal units since 1951 (12), in spite of the fact that several groups using donor blood preserved in acid citrate and dextrose $(22,27)$, or recently CPD blood $(21)$, have failed to find an effect on the decreased serum-ionized calcium. Even though the serum-ionized calcium reached values below $2.5 \mathrm{mg} / \mathrm{dl}$, both in the absence and in the presence of calcium supplements, tetany is a very rarely observed event during exchange transfusion. Finally, Walker and Neligan (35) abandoned calcium gluconate supplementation as early as 1955 without observing tetany in a series of 272 exchange transfusions. Thus, we advocate that injections of calcium at regular time intervals during exchange transfusions for hyperbilirubinemia with blood preserved in citrate, or citrate and phosphate should no longer be recommended as a prophylactic measure for preventing a decrease in serum-ionized calcium.

\section{CONCLUSIONS}

Parathyroid hormone secretion is inversely related to serum calcium concentrations in newborn infants. Maximal PTH responses are approached at serum levels close to the normal range. Iv calcium injections during exchange transfusion with blood preserved in citrate and phosphate do not prevent the decrease in serum-ionized calcium levels.

\section{REFERENCES AND NOTES}

1. Anast, C. S., Mohs, J. M., Kaplan, S. L., and Burns, T. W.: Evidence for parathyroid failure in magnesium deficiency. Science, 177: 606 (1972)

2. Andreatta, R. H., Hartmann, A., Jöhl, A., Kamber, B., Maier, R., Riniker, B. Rittel, W., and Sieber, P.: Synthese der Sequenz 1-34 von menschlichem Parathormon. Helv. Chim. Acta, 56: 470 (1973)

3. Arnaud, C. D., Tsao, H. S., and Littledike. T.: Radioimmunoassay of human parathyroid hormone in serum. J. Clin. Invest., 50: 21 (1971)

4. Bazett, H. C.: An analysis of the time-relation of electrocardiograms. Heart, 7: $354(1920)$

5. Blum, J. W., Fischer, J. A., Schwörer, D., Hunziker, W., and Binswanger, U.: Acute parathyroid hormone response: Sensitivity, relationship to hypocalcemia, and rapidity. Endocrinology, 95: 753 (1974)

6. Blum, J. W. Mayer, G. P., and Potts, J. T.. Jr.: Parathyroid hormone responses during spontaneous hypocalcemia and induced hypercalcemia in cows. Endocrinology, 95: 84 (1974)

7. Brewer, H. B., Jr., Fairwell, T., Ronan, R., Sizemore, G. W., and Arnaud, C. D. Human parathyroid hormone: amino-acid sequence of the amino-terminal residues 1-34. Proc. Nat. Acad. Sci. USA. 69: 3585 (1972)

8. Bronner, F., Golub, E. E., and Fischer, J. A.: The effect of vitamin D on renal calcium clearance. In: H. Fleisch, W. G. Robertson, L. H. Smith and W. Vahlensieck: Urolithiasis Research, p. 383 (Plenum Press, New York, 1976)

9. Coletti, R. B., Pan, M. W., Smith, E. W. P., and Genel, M.: Detection of hypocalcemia in suspectible neonates. N. Engl. J. Med., 290: 931 (1974)

10. David, L., and Anast, C. S.: Calcium metabolism in newborn infants. J. Clin Invest., 54: 287 (1974)

11. David, L., and Anast, C. S.: Evaluation of parathyroid function in newborns. In: 
B. Frame, A. M. Parfitt and H. Duncan: Clinical Aspects of Metabolic Bone Disease, p. 661 (Excerpta Medica, Amsterdam. 1973)

12. Diamond, L. K., Allen, F. H., Jr., and Thomas, W. O., Jr.: Erythroblastosis fetalis. VII. Treatment with exchange transfusion. N. Engl. J. Med., 244: 40 (1951)

13. Diem, K., and Lentner, C.: Mathematik und Statistik. In: Wissenschaftliche Tabellen, 7th Ed., p. 146 (Documenta Geigy, Basle, 1968)

14. Fischer, J. A., Binswanger, U., and Blum. J. W.: The acute parathyroid hormone response to changes in ionized calcium during phosphate infusions in the cow. Europ. J. Clin. Invest., 3: 15! (1973)

15. Fischer, J. A., Binswanger, U., and Dietrich, F. M.: Human parathyroid hormone: immunological characterization of antibodies against a glandular extract and the synthetic amino-terminal fragments $\mathrm{I}-12$ and $1-34$ and their use in the determination of immunoreactive hormone in human sera. J. Clin. Invest., 54 : 1382 (1974)

16. Gibson, J. G., Rees, S. B., McManus, T. J., and Scheitzlin, W. A.: A citratephosphate-dextrose solution for the preservation of human blood. Amer. J. Clin. Pathol., 28: 269 (1957)

17. Goldsmith, R. S., Furszyfer, J., Johnson, W. J., Fournier, A. E., Sizemore. G W., and Arnaud, C. D.: Etiology of hyperparathyroidism and bone disease during chronic hemodialysis. III. Evaluation of parathyroid suppressibility. $J$. Clin. Invest., 52: 173 (1973)

18. Herbert, L. A., Lemon, J., Jr., Peterson, J. R., and Lemon. E. J.: Studies of the mechanism by which phosphate infusion lowers serum calcium concentration. J. Clin. Invest., 45: 1886 (1966)

19. Hillman, L. S., Rojanasathit, S., Slatopolsky, E., and Haddad, J. G.: Serial measurements of serum calcium, magnesium, parathyroid hormone, calcitonin. and 25-hydroxy-vitamin $D$ in premature and term infants during the first week of life. Pediatr. Res., 11: 739 (1977)

20. Hohenwallner, W., and Wimmer, E.: The malachite green micromethod for the determination of inorganic phosphate. Clin. Chim. Acta, 45: 169 (1973)

21. Maisels, M. J., Friedman, Z., Marks, K. H., Uhrmann, S., Lee, C., and Denlinger, J. K.: Calcium homeostasis in exchange transfusion. Pediatr. Res., (abstract) 11: 537 (1977)

22. Maisels, M. J., Ting-Kai Li, B., Piechocki, J. T., and Werthman, M. W.: The effect of exchange transfusions on serum ionized calcium. Pediatrics, 53: 683 (1974)

23. Martell, A.: Section II: Organic Ligands. In: L. G. Sillén and A. E. Martell: Stability Constants of Metal-Ion Complexes. Special Publication No. 17, p 478 (The Chemical Society, Burlington House, London, 1964)

24. Mayer, G. P.: Effect of calcium and magnesium on parathyroid hormone secretion rate in calves. In: $R$. V. Talmage, M. Owen and J. A. Parsons: Calcium-regulating hormones, p. 122 (Excerpta Medica, Amsterdam, 1975)
25. Milner, R. D. G., and Woodhead, J. S.: Parathyroid hormone secretion during exchange transfusion. Arch. Dis. Childhood, 50: 298 (1975)

26. Niall, H. D., Sauer, R. T., Jacobs, J. W., Keutmann, H. T., Segre, G. V. O'Riordan, J. L. H., Aurbach, G. D., and Potts, J. T., Jr.: The amino-acid sequence of the amino-terminal 37 residues of human parathyroid hormone. Proc. Nat. Acad. Sci. USA, 71: 384 (1974)

27. Raddé, I. C., Parkinson, D. K.. Höfken, B., Appiah, K. E., and Hanley, W. B.: Calcium ion activity in the sick neonate: Effect of bicarbonate administration and exchange transfusion. Pediatr. Res., 6: 43 (1972)

28. Reifenstein, E. C., Jr., Albright, F., and Wells, S. L.: The accumulation, interpretation, and presentation of data pertaining to metabolic balances, notably those of calcium. phosphorus, and nitrogen. J. Clin. Endocrinol., 5: 367 (1945)

29. Reiss, E., Canterbury, J. M., Bercovitz, M. A., and Kaplan, E. L.: The role of phosphate in the secretion of parathyroid hormone in man. J. Clin. Invest., 49: 2146 (1970)

30. Segre, G. V., Habener, J. F, Powell, D., Tregear, G. W., and Potts, J. T., Jr.: Parathyroid hormone in human plasma. Immunochemical characterization and biological implication. J. Clin. Invest., 5I: 3163 (1972)

31. Silverman. R., and Yalow, R. S.: Heterogeneity of parathyroid hormone. Clinical and physiological implications. J. Clin. Invest., 52: 1958 (1973)

32. Tregear, G. W., Van-Rietschoten, J., Greene, E., Niall, H. D., Keutmann, H. T. Parsons, J. A.. O'Riordan, J. L., and Potts, J. T.. Jr.: Solid-phase synthesis of the biologically active N-terminal 1-34 peptide of human parathyroid hormone. Hoppe-Seylers, Zschr. Physiol. Chem.. 355: 415 (1974)

33. Tsang, R. C., Chen, I-W., Friedman. M. A., and Chen, I.: Neonatal parathyroid function: Role of gestational age and postnatal age. J. Pediatr., 83: 728 (1973)

34. Tsang, R. C., Chen, I.-W., Friedman, M. A., Gigger, M., Steichen, J., Koffler, H., Fenton, L., Brown, D., Pramanik, W., Strub, R., and Joyce, T.: Parathyroid function in infants of diabetic mothers. J. Pediatr., 86: 399 (1975)

35. Walker, W., and Neligan, G. A.: Exchange transfusions in haemolytic disease of the newborn. Brit. Med. J., I: 682 (1955)

36. Wiener, A. S., and Wexler, I. B.: Results of therapy of erythroblastosis with exchange transfusions. Blood, 4: 1 (1949)

37. This paper is dedicated to Professor Andrea Prader, Department of Pediatrics, University of Zurich on the occasion of his 60th birthday.

38. A preliminary report of part of this work has been published. Clin. Res., 24: 372A (1976)

39. This research was supported in part, by the Swiss National Science Foundation grant 3.739-0.76.

40. Requests for reprints should be addressed to: Dr. J. A. Fischer, Orthopädische Universitätsklinik Balgrist, Forchstrasse 340, 8008 Zurich, Switzerland.

41. Received for publication April 4, 1978

42. Accepted for publication August 10, 1978 